Original article

\title{
Birth dimensions, severe mental illness and risk of type 2 diabetes in a cohort of Danish men born in 1953
}

\author{
Marina Garriga ${ }^{\mathrm{a}, *}$, Marie K Wium-Andersen ${ }^{\mathrm{b}}$, Ida K Wium-Andersen ${ }^{\mathrm{b}, \mathrm{c}}$, \\ Merete Nordentoft ${ }^{\mathrm{d}}$, Merete Osler ${ }^{\mathrm{b}, \mathrm{e}}$ \\ a Bipolar and Depressive Disorders Unit, Institute of Neuroscience, Hospital Clinic Barcelona, IDIBAPS, CIBERSAM, University of Barcelona, Barcelona, \\ Catalonia, Spain \\ ${ }^{\mathrm{b}}$ Center for Clinical Research and Prevention, Bispebjerg and Frederiksberg Hospitals, Frederiksberg, Denmark \\ ${ }^{\mathrm{c}}$ Psychiatric Center Copenhagen, Department O, Copenhagen, Denmark \\ ${ }^{\mathrm{d}}$ Mental Health Centre Copenhagen, Copenhagen University Hospital, iPSYCH The Lundbeck Foundation Initiative for Integrative Psychiatric Research, \\ Denmark \\ e Section of Epidemiology, Department of Public Health, University of Copenhagen, Center for Clinical Research and Prevention, Bispebjerg and Frederiksberg \\ Hospitals and Danish Ageing Research Center, Department of Public Health, University of Southern Denmark, Denmark
}

\section{A R T I C L E IN F O}

\section{Article history:}

Received 13 June 2019

Received in revised form 29 August 2019

Accepted 29 August 2019

Available online 7 September 2019

\section{Keywords:}

Birth weight

Ponderal index

Type 2 diabetes mellitus

Schizophrenia

Severe mental illness

\begin{abstract}
A B S T R A C T
Background: Birth dimensions have been associated with increased risk of both, severe mental illness and type 2 diabetes in adulthood, however, any influence on their co-occurrence has never been examined. This cohort study examine whether birth weight/ponderal index explain or modify the later association between severe mental illness and risk of type 2 diabetes.

Methods: The Metropolit cohort included 10,863 Danish men born in 1953 with information from age at conscription (between1971-84) until February $15^{\text {th }}, 2018$. Severe mental illness was defined as the exposure and information was retrieved from the national Danish health registries. Information on type 2 diabetes diagnosis or oral antidiabetic prescriptions was also obtained, as they were the outcome of interest. Information on birth weight/ponderal index was available from birth certificates. Cox proportional hazards regression models were used to estimate the associations and interactions were tested.

Results: After 47.1 years of follow-up, 848 (7.8\%) and 1320 (12.2\%) men developed a severe mental illness or diabetes, respectively. Men with severe mental illness presented higher risk of subsequent diabetes $(\mathrm{HR}=1.92 ; 95 \% \mathrm{CI}, 1.61-2.30)$. This association was stronger in severe mental ill men with low birth weight $(\mathrm{HR}=3.58 ; 95 \% \mathrm{CI}, 2.11-6.07)$, than in those normal birth weight $(\mathrm{HR}=1.79 ; 95 \% \mathrm{CI}, 1.45-2.20)$. This effect modification was most evident for men diagnosed with schizophrenia.

Conclusions: Birth information on birth weight/ponderal index could be of interest in diabetes screening on severe mental ill populations (especially in schizophrenia) since they might play a critical role in the increased risk of type 2 diabetes following severe mental illness.
\end{abstract}

(c) 2019 Elsevier Masson SAS. All rights reserved.

\section{Introduction}

Individuals with severe mental illnesses are prone to develop different somatic diseases [1-3], with schizophrenia [2], bipolar disorder [4] and major depression [5] repeatedly associated with increased risk of type 2 diabetes [6]. Multiple explanations have been proposed, including impaired lifestyle (e.g. scarce physical activity, unhealthy dietary habits, tobacco use) [7-9], the

\footnotetext{
* Corresponding author at: Hospital Clínic, 170 Villarroel St., 08036, Barcelona, Catalonia, Spain.

E-mail address: magarriga@clinic.cat (M. Garriga).
}

psychiatric illness itself (e.g. negative and cognitive symptoms) [10], poor medical monitoring, psychopharmacological treatment [8-12], and common biological pathways (epigenetic [13], immunological [14], telomeric [15] and endocrinological [16] changes) which might also explain the increased risk of diabetes in naïve treated patients [16,17].

The "Developmental Origins of Health and Disease" hypothesis proposes that intrauterine adverse environments could affect the physiology of the offspring and hereby increase the later risk of somatic diseases, thought fetal programming models [18-20]. Hence, indicators of impaired fetal growth, such as low birth weight, low ponderal index (a weight-height parameter related with the fetal growth pattern) and small-for-gestational-age, have 
shown to be related with both, somatic diseases and mortality, in adult age [19,21-24] as well as with later psychopathology [25-31].

Several studies on sub-optimal environment in fetal life have already shown that birth dimensions related to fetal growth, such as low birth weight, are risk factors for both, severe mental illness [32,33] and type 2 diabetes [22,34,35], separately, even after accounting for potential confounding factors such as heritability, lifestyle and socioeconomic environment. On the schizophrenia field, it has been proposed that severe mental ill patients might present a vulnerability to develop both, the mental and metabolic disease, due to a higher epidemiologic ratio of diverse obstetric complications $[36,37]$ (such as extremes on birth weight), with the presence of glucose disturbances already present at the onset of the psychiatric illness [38]. In this line of research, no studies have explored the role of birth dimensions such as birth weight and ponderal index on the association between severe mental illness and type 2 diabetes.

In this study, we tested if the potential association between severe mental illness and type 2 diabetes was explained or modified by birth weight or ponderal index, as markers of fetal growth.

\section{Methods}

\subsection{Study population}

The Metropolit cohort includes 11,532 men born in 1953 in the Copenhagen Metropolitan area and has been described elsewhere [39]. A total of 10,863 men were included after excluding those with missing information on birth weight or height, those born twins/ triplets and those who died or emigrated before age of conscription (see Fig. 1 for cohort flowchart).

\subsection{Exposure: severe mental illnesses}

Information on admissions to a psychiatric or somatic ward from 1969 or 1977, respectively, and until end of follow-up (February $15^{\text {th }} 2018$ ) was obtained by linkage with the Danish Psychiatric Central Registry and the Danish National Patient Registry using the person identification number as key. The registers hold individual data on type of patient contact (inpatient information from 1969/1977; emergency room and outpatient information from 1995), diagnosis, and date of admission and discharge for all hospital admissions in Denmark. Diagnoses have been coded according to the 8th Revision of the International Classification of Diseases (ICD8) from 1969 to 1995 , and the $10^{\text {th }}$ Revision (ICD10) from 1995 and onwards. In the present study, men were registered at their first mental health contact with any of the severe mental illness diagnoses outlined in Fig. 1. Due to a considerable diagnostic overlap between major depression and bipolar disorder $(n=375)$, the final sample was divided into two clinical psychiatric spectrums: schizophrenia and related disorders and affective disorders (see Supplementary eFig. 1 in Supplementary Material).

\subsection{Outcome: type 2 diabetes MELLITUS}

Information on type 2 diabetes was derived according to ICD-8/ ICD-10 codes from the Danish National Patient Register from 1977

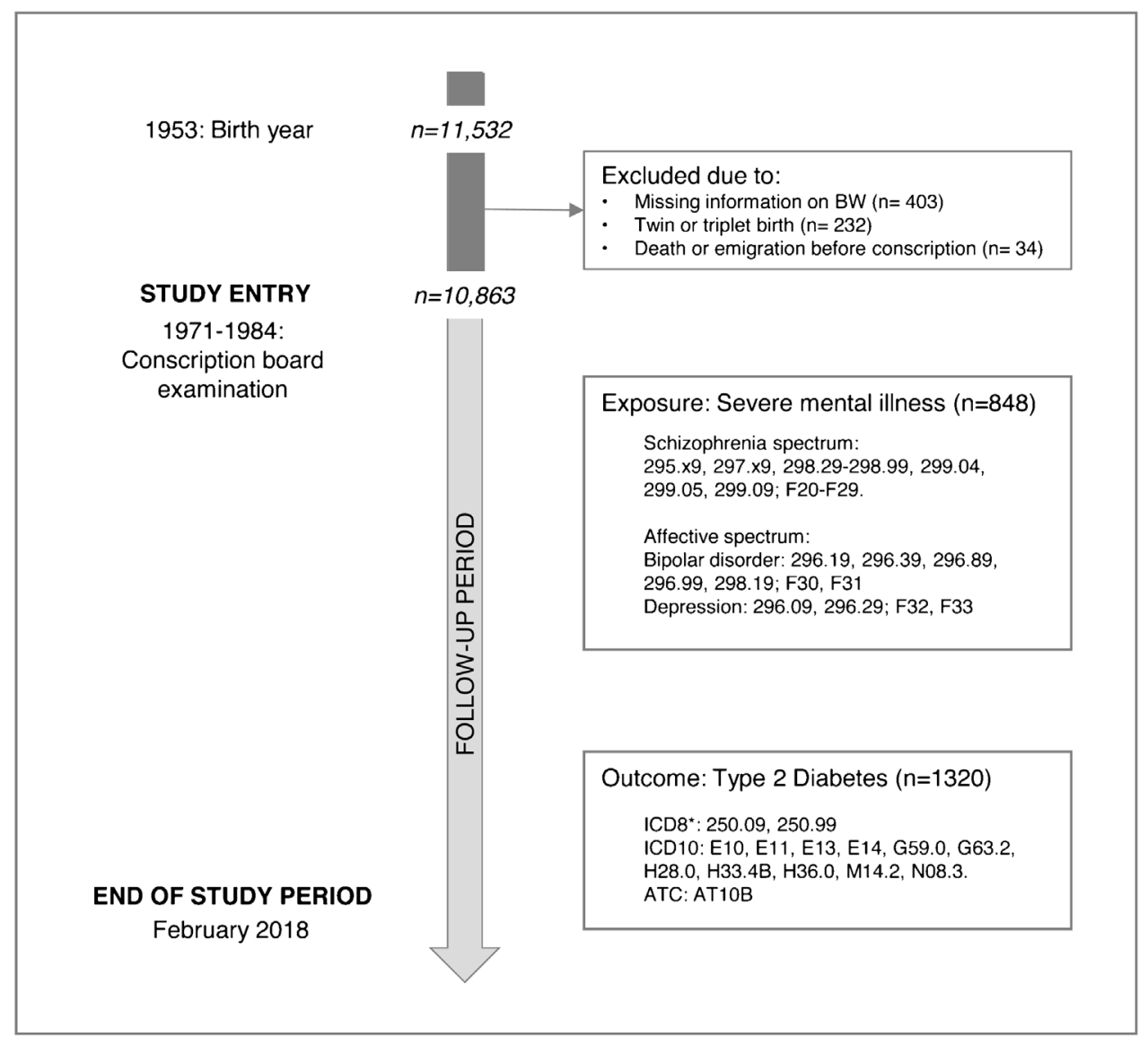

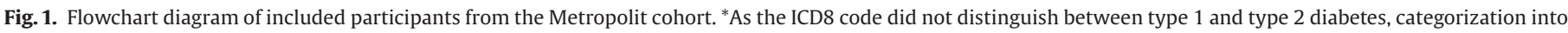
type 1 and type 2 diabetes in the ICD 8 was based age ( $<35$ years defined as Type 1 diabetes and $\geq 35$ years as type 2 diabetes). 
to end of follow-up. In addition to hospital diabetes diagnoses, we also identified antidiabetic prescriptions from the Danish National Database of Reimbursed Prescriptions as many patients with diabetes are treated only in primary care. The prescription database contains data from 1995 on all reimbursed drugs dispensed at all Danish pharmacies, and the information includes the Anatomical Therapeutic Chemical (ATC) classification system codes and dispensing dates. Selected ICD and ATC codes are shown in Fig. 1.

Outcome of interest was defined as first hospital discharge or death from a diagnosis of diabetes or a diabetic complication or as first prescription of an antidiabetic drug from 1995 or later, whichever came first. If uncertainty of diabetes type 1 or 2 diagnosis occurred, a cut-off age of 35 years old was used, where those above were considered to present type 2 diabetes.

\subsection{Fetal growth: birth weight and ponderal index}

Birth weight and ponderal index were used as proxy measures for fetal growth and gestational age at birth as these covariables were not available. Birth weight was recorded in $100 \mathrm{~g}$ groups and analyzed in three categories: $\leq 2500$ low birth weight; 2500-4000 normal birth weight; and $\geq 4000 \mathrm{~g}$ high birth weight. Ponderal index, calculated as birth weight $[\mathrm{Kg}] /$ birth length [meters $]^{3}$, was also included as it is theoretically assumed to measure fetal growth and thereby discriminate between intra-uterine well-fed (high ponderal index) and disproportionate growth restricted newborns (low ponderal index) [40]. Ponderal index was analyzed as threecategory variable ( $1^{\text {st }}$ quintile; $2^{\text {nd }}-4^{\text {th }}$ quintile; 5 th quintile).

\subsection{Other covariables}

Dates on death and emigration were followed from 1968 until February $15^{\text {th }} 2018$ by register linkage with the Danish Civil Registration System. From the birth certificates, we further included maternal age in years (categorized as $<20,20-34.9$ and $\geq 35 y 0$ ) and paternal occupational social class (categorized as white collar worker (self-employed and salaried employee), blue collar worker (skilled and unskilled workers) or unknown at the time of delivery).

All young Danish men are required by law to be physically and mentally examined at the Danish conscription board to evaluate their eligibility for military service. This information was collected manually from conscript board registers. From the conscript examinations (approximately at age 18-24), we included information on educational level categorized as basic (7-10 years: primary school with or without finals), middle (9-12 years: middle and secondary school, or skilled training in industry, trade and craft) and high ( $<12$ years: secondary school final, medium length or higher education). We also retrieved cognitive ability information assessed by the Børge Priens Prøve (BPP), which has been shown to correlate with the Wechler Adult Intelligence Scale [41]. The BPP total continuous score (from 0 to 78 ) was categorized in tertiles (low, medium and high IQ scores). Body height and weight at conscription were used for calculation of Body Mass Index $\left(\mathrm{BMI}=\right.$ weight $[\mathrm{kg}] /$ height $\left.[\mathrm{m}]^{2}\right)$ and later categorized into less than 18.5 (underweight), 18.5-25 (normal weight), and $\geq 25$ (overweight/obesity). These variables were included as they were assumed to be relevant based on previous research associating them with both development of severe mental illness and diabetes.

\subsection{Statistical analyses}

Stata version 13.1 on Windows was used for all statistical analyses. Missing values were coded and included in the analyses (see Table 1). Baseline characteristics of study subjects were calculated using Chi-square tests due to the categorical nature of the variables.

The association between severe mental illness and diabetes was analyzed using Cox proportional hazards regression models with age as the underlying time scale and provided hazard ratios (HRs) with 95\% confidence intervals (CI). Cohort members were followed from age at conscription (between 1971-84) and until first diagnosis of type 2 diabetes, a diagnosis of type 1 diabetes (as this meant individuals were no longer at risk of receiving a diagnosis of type 2 diabetes), first prescription from a non-insulin antidiabetic drug, death, emigration, or end of follow-up (February $\left.15^{\text {th }}, 2018\right)$, whichever came first. For individuals who missed the date for attending conscription ( $n=145)$, study entry was defined as age at January $1^{\text {st }}, 1971$. Further, men who had died $(n=16)$ or emigrated $(n=18)$ before 1971 were excluded, leaving 10,863 men to be included in the analyses. The exposures (schizophrenia, affective disorders, and the combined variable of severe mental illness) were included as time-dependent variables in separate models so that men diagnosed with any severe mental illness changed exposure status from non-exposed to exposed at time of first diagnosis. This was done to avoid immortal time bias. Prevalent cases of psychiatric disorders at the time of conscription $(n=14)$ were included as exposed at the time of study entry. No individuals had diabetes at the time of study entry. The proportional hazards assumption was tested graphically by plotting $-\log (-\log ($ survival $))$ vs. $\log$ (follow-up time) and no important violations were found.

First, we examined the association between severe mental illness and type 2 diabetes in three models where covariates were included sequentially. Next, to study whether fetal growth markers could explain the associations between severe mental illness and type 2 diabetes, birth weight was included into the model as a categorical variable (low, normal, or high). In this model, we further adjusted for birth length. We repeated all sequential analyses using ponderal index in three categories (low, middle, or high) instead of birth weight. Finally, to examine if fetal growth markers modified the association between severe mental illness and type 2 diabetes, interaction terms "birth weight*severe mental illness" and "ponderal index*severe mental illness" were included in the regression models and differences in goodness of fit compared to the original model were tested using likelihood ratio tests.

\section{Results}

\subsection{DISTRIBUTION OF COHORT COVARIATES}

During follow-up (median of 47.1 years, IQR 44.9-47.1 years), $7.8 \%(n=848)$ men were diagnosed with severe mental illness, while $12.2 \%(n=1320)$ developed type 2 diabetes. The distribution of covariates in the cohort as well as in the severe mental illness subgroups and diabetes are shown in Table 1 . Severe mental illness and diabetes were more frequent in men with basic educational level ( $p<0.01$ and $p=0.03$, respectively) and lower cognitive scores $(\mathrm{p}<0.01$ for each). Underweight in young adulthood was associated with severe mental illness $(\mathrm{p}<0.01)$, and overweight/ obesity was related with type 2 diabetes. Severe mental illness was not associated with fetal growth, while diabetes was more frequent in men with reduced fetal growth $(p<0.01$ for both, the lowest category of birth weight and ponderal index compared to the normal/middle groups).

\subsection{Associations between severe mental illness and Diabetes}

The Cox regression models to evaluate the longitudinal association between severe mental illness and type 2 diabetes showed that 
Table 1

The distribution (\%) of severe mental illness and type 2 diabetes in 10,863 Danish men born in 1953 in relation to covariates.

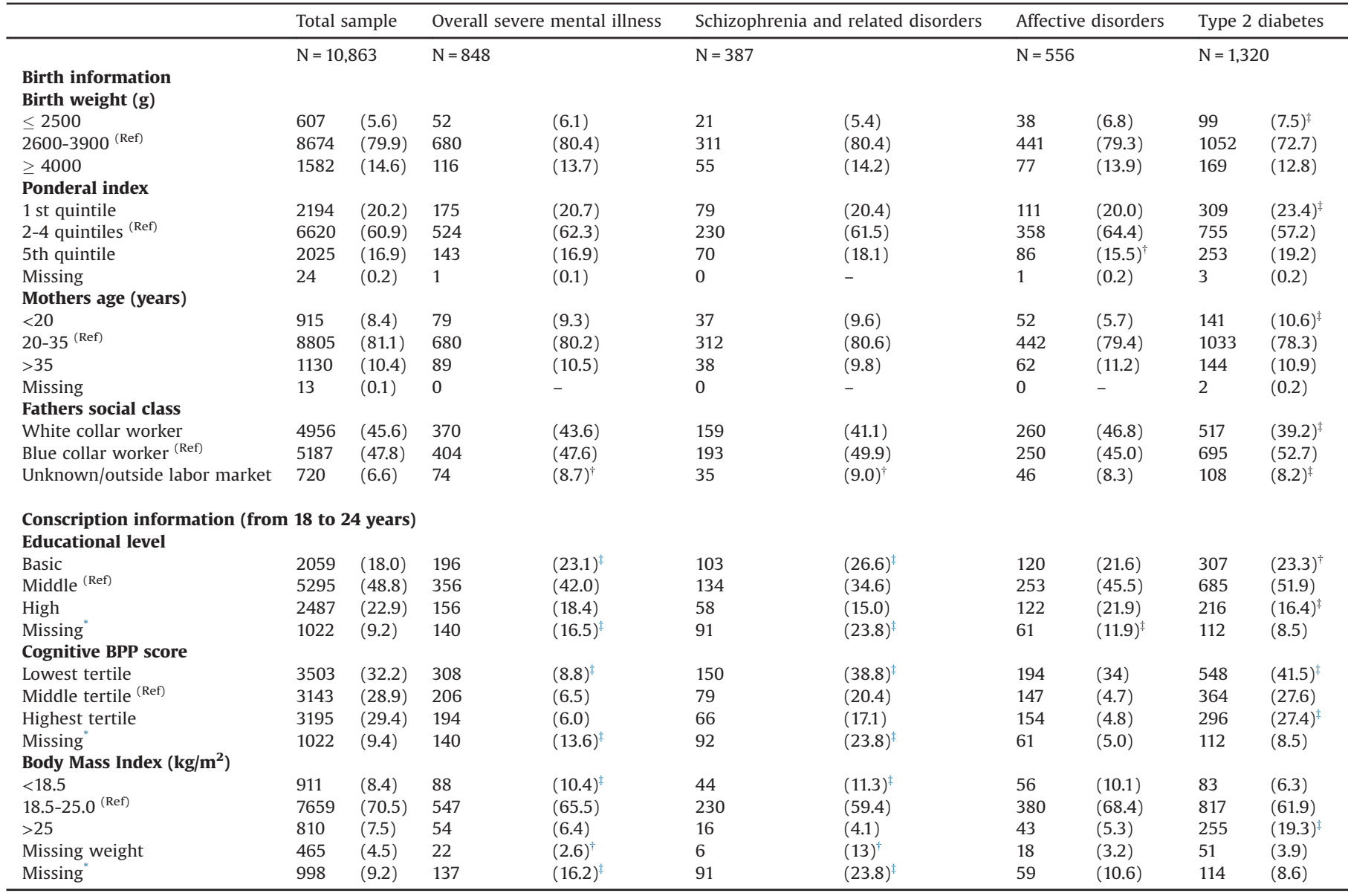

Chi-square test was performed in each marked category versus reference (Ref) group:

${ }^{\dagger}$ p-values lower than 0.05 .

¥ p-values lower than 0.01 .

* Missing values mainly due to exemption from conscription examination.

men who developed severe mental illness had higher risk of subsequent type 2 diabetes (hazard ratios $(\mathrm{HR})=1.92$ [95\% confidence interval (CI): 1.61-2.30]). This estimate was only slightly attenuated when we first included covariates such as mother's age, father's occupational status, educational level, cognitive performance and BMI at conscription ( $\mathrm{HR}=1.85$ [1.55-2.23] as well as when later including fetal growth markers covariates (Table 2). Similar patterns were seen when analyses were restricted to men with schizophrenia and related disorders $(\mathrm{HR}=1.83$ [1.39-2.39]) and affective spectrum disorders (HR = $1.91[1.52-2.41])$.

Table 2

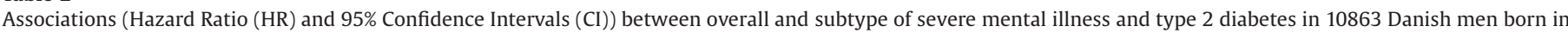
1953 followed from 1971 to 2018.

\begin{tabular}{|c|c|c|c|c|c|c|c|}
\hline & No. total & No. T2DM & Model 1 HR (95 \% CI) & Model 2 HR (95\% CI) & Model 3 HR (95\% CI) & Model 4 HR (95\% CI) & Model 5 HR $(95 \% \mathrm{CI})$ \\
\hline \multicolumn{8}{|c|}{ Overall SMI } \\
\hline No & 10015 & 1175 & 1 [reference] & 1 [reference] & 1 [reference] & 1 [reference] & 1 [reference] \\
\hline Yes & 848 & 145 & $1.92(1.61-2.30)$ & $1.88(1.57-2.25)$ & $1.85(1.55-2.23)$ & $1.85(1.55-2.23)$ & $1.86(1.55-2.23)$ \\
\hline \multicolumn{8}{|c|}{ Schizophrenia and related disorders } \\
\hline No & 10476 & 1264 & 1 [reference] & 1 [reference] & 1 [reference] & 1 [reference] & 1 [reference] \\
\hline Yes & 387 & 56 & $1.83(1.39-2.39)$ & $1.78(1.36-2.33)$ & $1.79(1.36-2.36)$ & $1.80(1.35-2.36)$ & $1.81(1.38-2.37)$ \\
\hline \multicolumn{8}{|c|}{ Affective disorders } \\
\hline No & 10307 & 1214 & 1 [reference] & 1 [reference] & 1 [reference] & 1 [reference] & 1 [reference] \\
\hline Yes & 556 & 106 & $1.91(1.52-2.41)$ & $1.86(1.47-2.34)$ & $1.84(1.46-2.23)$ & $1.84(1.46-2.32)$ & $1.85(1.42-2.34)$ \\
\hline
\end{tabular}

Model 1: unadjusted.

Model 2: adjusted for mother's age and father's occupational status.

Model 3: further adjusted for education, IQ and BMI at conscription.

Model 4: model $3+$ further adjusted for BW (and also includes adjustment for birth length).

Model 5: model $3+$ further adjusted for PI.

BW = Birth Weight; PI = Ponderal Index; SMI: Severe mental illness; T2DM: type 2 diabetes. 
3.3. The impact of birth weight and ponderal index on the association between severe mental illness and diabetes

Next, we tested whether these associations between severe mental illness and diabetes were modified by birth dimensions such as birth weight and ponderal index. Fig. 2 illustrates the associations (unadjusted HR) between severe mental illness and type 2 diabetes in the three categories of birth weight with individuals with normal birth weight (2600-3900 g) and no severe mental illness as reference group. Men born with low birth weight who developed severe mental illness had a higher risk of diabetes $(\mathrm{HR}=3.58$ [2.11-6.07]), than men with normal birth weight and a severe mental illness $(\mathrm{HR}=1.79[1.45-2.20])$ or men with low birth weight who did not develop severe mental illness (HR = 1.31 [1.051.63]). After further adjustment for maternal age, parental occupational status, educational level, cognitive performance and BMI at conscription we found that the observed HR only attenuated slightly (see Supplementary Fig. 2). These results were similar when examining schizophrenia and affective spectrum disorders separately (see Fig. 2), with the highest observed risk for diabetes amongst those born with a low birth weight and schizophrenia $(H R=5.66$ [2.53-12.64]). Similarly, risk estimates only attenuated slightly, when further adjusting for the variables mentioned above (Supplementary Fig. 2).

Thus, the risk estimate for those exposed to both, low birth weight and severe mental illness $(\mathrm{HR}=3.58)$, was slightly higher than what would be expected under a multiplicative model $\left(\mathrm{HR}_{\text {expected }}\right.$ of $\left.1.31 \times 1.79=2.34\right)$. Same tendency was observed for those combining high birth weight $(>4000 \mathrm{~g})$ and severe mental illness $\left(\mathrm{HR}_{\text {observed }}=1.95[1.24-3.08] \mathrm{vs}\right.$. $\left.\mathrm{HR}_{\text {expected }}=1.52\right)$. When the analyses were restricted to schizophrenia and affective spectrum disorders, we found that the risk of diabetes in men with low birth

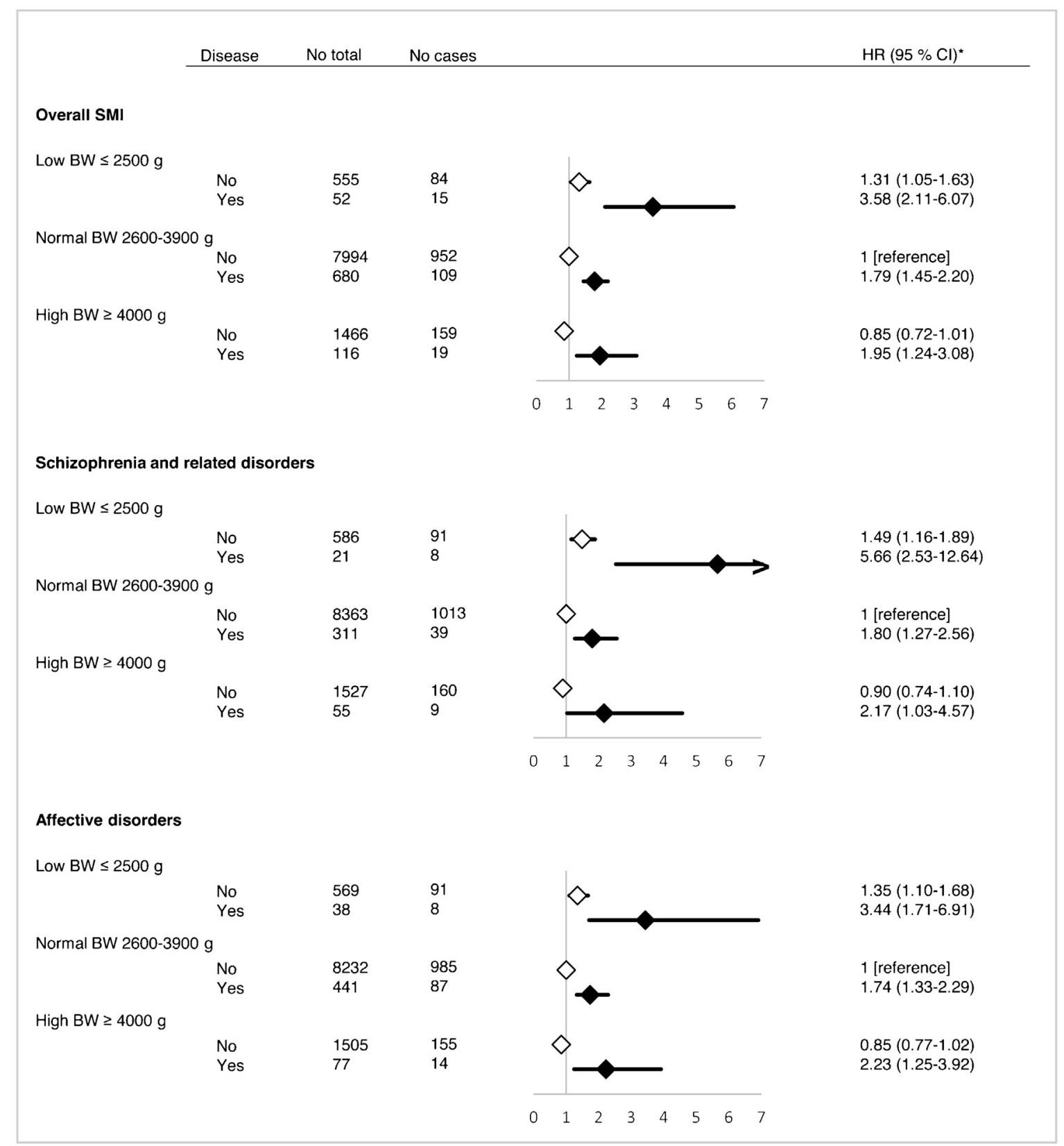

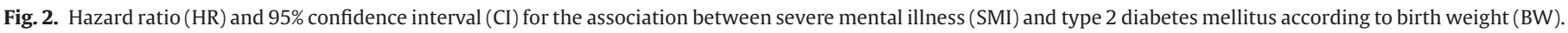
Black and white diamonds represents those with or without severe mental illness, respectively. *All analyses are unadjusted. 


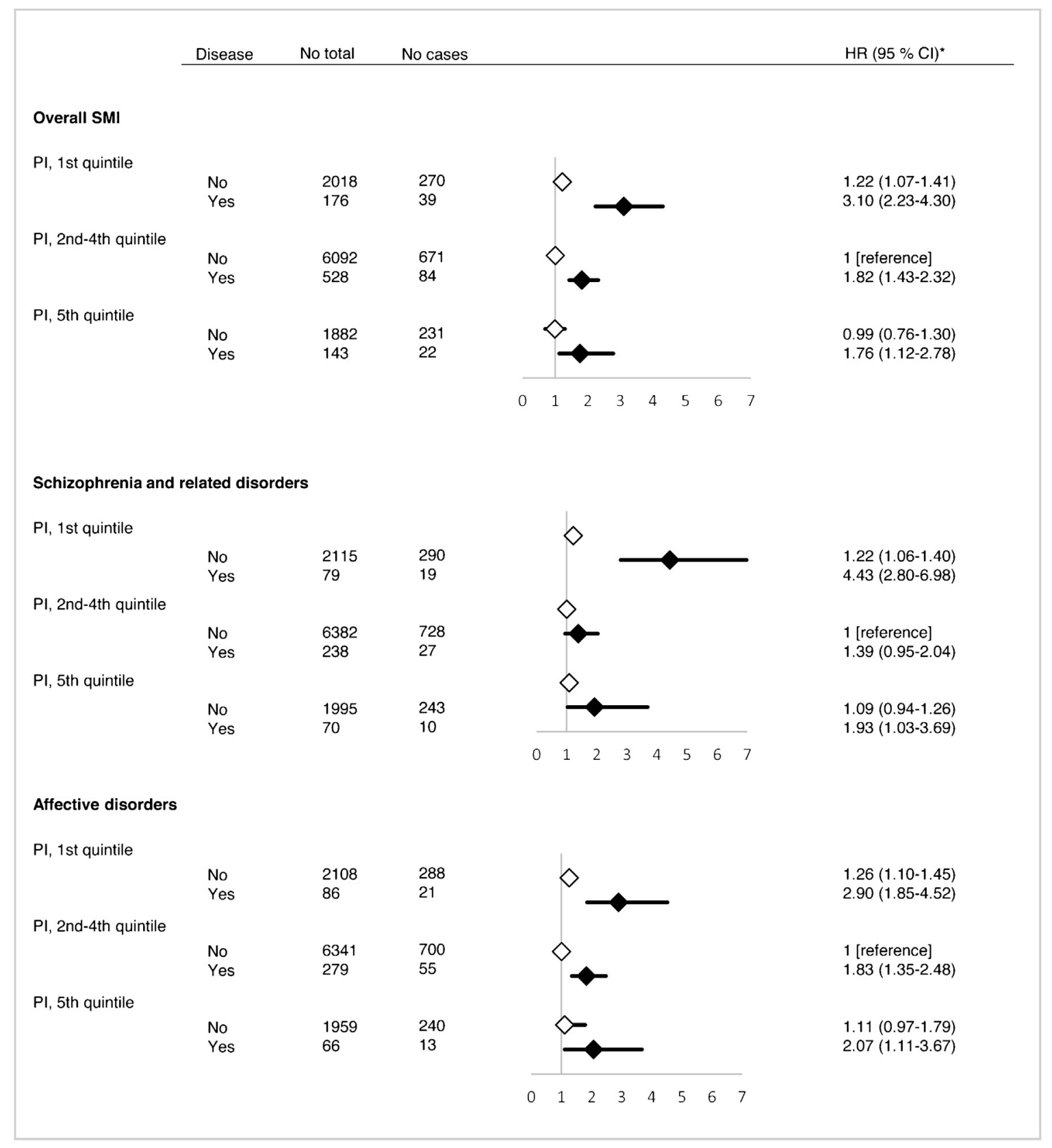

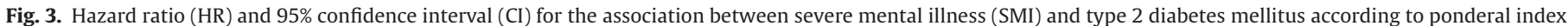
(PI). Black and white diamonds represents those with or without severe mental illness, respectively. *All analyses are unadjusted.

weight and schizophrenia was much larger $\left(\mathrm{HR}_{\text {observed }}=5.66\right.$ $[2.53-12.64])$ than expected $\left(\mathrm{HR}_{\text {expected }}=2.68\right)$ with a significant interaction term (birth weight*severe mental illness; $\mathrm{p}=0.03$ ). However, due to low power the risk estimate was imprecisely estimated.

We also explored if ponderal index modified the effect of severe mental illness on risk of developing type 2 diabetes on unadjusted (Fig. 3) and adjusted models (Supplementary Fig. 3). The results of these analyses were similar to those obtained from birth weight, albeit with slightly attenuated risk estimates. We observed how those men born with low ponderal index who developed a severe mental illness had a higher risk of type 2 diabetes (HR $=3.10$ [2.234.30]), than men born with normal ponderal index and a severe mental illness $(\mathrm{HR}=1.82$ [1.43-2.32]) or men with low ponderal index who did not develop severe mental illness (HR $=1.22$ [1.071.41]). These results were also present in adjusted models
(Supplementary Fig. 3) and when analyzing the two severe mental illness subgroups. Again, the largest risk effect for diabetes was in those born with a low ponderal index and schizophrenia $(\mathrm{HR}=4.43$ [2.80-6.98]). However, low ponderal index did not modify the association between severe mental illness (overall and by subgroup) and type 2 diabetes with a borderline significant interaction term (ponderal index*severe mental illness) for those in the schizophrenia group $(\mathrm{p}=0.08)$.

\section{Discussion}

In this population-based cohort study of Danish men followed from age 18 to age 65 , we found that the risk of type 2 diabetes was nearly doubled in men with severe mental illness compared to men without. The association was only slightly attenuated when adjusted for social factors, birth dimensions or BMI in 
young adulthood, suggesting that birth dimensions such as birth weight and ponderal index were not an important confounder for this association. On the other hand, in the models aimed to test if birth dimensions related with fetal growth modified this association, the risk estimates were higher than the expected in men with extremes birth weight/ponderal index and severe mental illness, which indicated an interaction between birth dimensions and severe mental illness on the risk of diabetes. This was most evident for men diagnosed with schizophrenia.

Our results are consistent with previous research showing that the frequency of type 2 diabetes is two-fold higher in people with severe mental illness that in the general population $[3,4,42]$. Although fetal birth dimensions, socioeconomic factors, and lifestyle have been associated with both, severe mental illness and diabetes, later adjustment for mothers' age, fathers' socioeconomic position, BMI and cognitive performance at conscription only explained a minor part of this association in our cohort. Our current understanding of the complex mechanisms linking severe mental illness and increased risk for diabetes mellitus has greatly improved in the past 15 years [43]. Possible related mechanisms might include shared genetic and environmental factors as well as effects of the psychiatric illness (e.g., cognitive impairment, negative and depressive symptoms, poor physical monitoring. . .) and its psychopharmacological treatment. However, these multiple and complex factors that might start together in an earlylife common pathway (where processes such as low grade inflammation as well as subtle metabolic disarrangements are emerging since the fetal life) should be investigated in more detail in order to improve current knowledge of fetal programming models $[2,17,43,44]$.

As expected, the increased association between severe mental illness and type 2 diabetes was stronger in men with low birth weight and the interaction was replicated for ponderal index. Furthermore, this association was especially present in patients with schizophrenia. Besides the lack of similar studies on affective spectrum disorders and diabetes, these results are in line with previous research on naïve and treatment-resistant patients with schizophrenia, low birth weight and antipsychotic induced weight gain as outcome $[45,46]$. Cross sectional results have shown an increased obesity due to antipsychotics in those with low birth weight and a treated-resistant psychosis in comparison with naïve patients [45]. However, when doing prospective follow-up studies, of psychotic patients starting obesogenic antipsychotics (such as olanzapine and clozapine), birth weight did not present the same modifier effect on antipsychotic induced weight gain [46]. After 16-18 weeks of antipsychotics, low birth weight only predicted weight gain in naïve patients starting their first antipsychotic, while these results were not replicated in patients that had been already treated (psychotic treated resistant patients) [46]. Other factors such as unhealthy lifestyle, older age, medical co-morbidities or previous antipsychotic medication have to be then also considered. Combined, the present results adds to the hypothesis that posits that adverse intrauterine environment (fetal programming) primes the offspring to become more vulnerable to metabolic risk factors (such as type 2 diabetes) and severe mental illness $[18,20,32,47]$. Still, the high level of co-morbidity and the early mortality due to cardiovascular and metabolic related diseases observed in SMI patients [48] might not be completely integrated under this approach. Opposed to the evidence which links impaired fetal growth (extremes on birth weight/ponderal index) with the later development mental illness and diabetes in a separated mechanism, a more heuristic concept (the "thrifty psychiatric phenotype") [17], proposes that subjects who experienced menaces during the intrauterine life might be at higher risk of developing mental illness in later life with contemporaneous anomalies in metabolic programming through an abnormal glycemic response.

We did not include use of antipsychotic medication in our analyses as we wanted to answer the question if fetal growth might influence in the later development of type 2 diabetes in severe mental ill patients independently of treatment. Antipsychotic medications have shown to increase the risk of diabetes and have been used during the study period which could have confounded our results $[49,50]$. However, glucose abnormalities have been previously found in antipsychotic naïve patients suffering from both, psychotic and affective disorders [16,51]. Thus, a recent population-based cohort study on psychotic patients showed increased endogenous risk of diabetes in antipsychotic-naïve patients compared with people without schizophrenia [42], strengthening the hypothesis that severe mental illness in itself increases the endogenous vulnerability for diabetes despite the pharmacological treatment.

Finally, in our analyses of a potential modifying effect of fetal growth, we additionally observed that within men who developed severe mental illness (especially schizophrenia), there seemed to be a U-shaped relationship between fetal growth and type 2 diabetes, which has been previously reported in non-psychiatric populations [34,35,52] (Figs. 2 and 3). Contrary, for men without mental illness, the relation between fetal growth markers and diabetes seemed more linear. Both, U-shaped and a linear inverse relationships between fetal growth markers and the risk of type 2 diabetes have been previously described in non-psychiatric populations [34,35,52], where sample characteristics, differences in the categorization of the variables and in the use of covariates might play a role in this discrepancies.

\subsection{Strengths and limitations}

The present study includes a population-based sample of Danish men born in 1953, followed over nearly 50 years in nationwide registers using the unique Danish person identification number as key. This allows virtually complete follow-up, making bias due to loss-to-follow-up unlikely. The follow-op period covers the ages where most cases of severe mental illnesses diabetes develop. We had prospectively collected information on birth dimensions and conscript board examinations, which eliminate risk of recall bias.

However, the study also has limitations. Our results were based on a cohort of Danish men (Caucasian race), and the findings may not be generalized to the different ethnicities or female gender. On gender regard, available studies do not indicate gender differences on the risk of diabetes following severe mental illness [53]. Taking all together, we have no reasons to believe that our finding should not adhere to women. However, studies including women or Asian populations have also found that severe mental illness is associated with increased risk of type 2 diabetes. Misclassification of severe mental illness could be present since we only had hospital diagnoses (since 1969) and outpatient clinics information from 1995 and information from psychiatric practices or general practitioners was not available. Hence, it is possible that some men were falsely coded as non-exposed of severe mental illness. However, any such underreporting of the exposure would only tend to underestimate the association. Also, the Danish National Patient Register might not include the milder cases of diabetes treated only in general practice. Consequently, we further included prescription register data on antidiabetic medication for case ascertainment which was, however, only available from 2004. Some cases of bipolar disorder could be firstly diagnosed as unipolar major depression; consequently, we decided to analyze the two forms of affective disorder together (affective disorders) while presenting results in a more conservative manner. Despite 
the fact that several confounders were included in the analyses, we lacked data on genetic disposition and maternal health which determine low birth weight and disease risk of offspring [54], however adjustment for birth dimensions did not explain the association between severe mental illness and diabetes. People with severe mental illness are likely to have a poorer lifestyle and suffer from other somatic diseases, but such factors were considered as mediators of the association and consequently not adjusted for.

\subsection{Conclusion}

In conclusion, men with severe mental illness had higher risk of type 2 diabetes than men without. Birth dimensions did not explain the association but seemed to modify it suggesting that men with low birth weight or low ponderal index had higher risk of developing type 2 diabetes following severe mental illness, especially schizophrenia. The evaluation, not only of birth weight/ponderal index, but also different early stressful events (e.g. obstetric complications and other birth dimensions), during pregnancy and initial years such as infant/childhood trauma [37,55], might help understanding which patients will be at greater risk of developing diabetes while helping in the implementation of more targeted interventions in selected patients, especially in patients with schizophrenia.

\section{Disclosures}

M Garriga has received grants and served as consultant or advisor for Ferrer, Lundbeck, Janssen, Spanish Ministry of Economy and Competitiveness, Instituto de Salud Carlos III through a 'Rio Hortega' contract (CM17/00102), and Centro de Investigación Biomédica en Red de Salud Mental (CIBERSAM).

\section{Funding/support}

M Garriga received funding from the Spanish Ministry of Economy and Competitiveness,Instituto de Salud Carlos III through a 'R1o Hortega' contract (CM17/00102, to Dr. Garriga), FEDER, Centro de Investigación Biomédica en Red de Salud Mental (CIBERSAM), Secretaria d'Universitats i Recerca del Departament d'Economia i Coneixement (2017SGR1365), and the CERCA Programme / Generalitat de Catalunya.

MK Wium-Andersen received funding from the Lundbeck Foundation.

I Wium-Andersen received funding from the Lundbeck Foundation and the Jascha Foundation.

The revitalization of Metropolit cohort has been funded by grants from the Lundbeck Foundation, the Danish health Insurance Fund, Danish heart Association and the Danish Fund for Independendt Research (grant number 8020-00031B)

Merete Nordentoft received funding from the Lundbeck Foundation (iPSYCH).

The different funding sources had no involvement in conduct of the research or in the preparation of the present paper.

\section{Declaration of Competing Interest}

Other authors declare no conflict of interests for this paper.

\section{Acknowledgements}

We thank all those who initiated and/or continued the Metropolit study: K Svalastoga, E Høgh, P Wolf, T Rishøj, G Strande-Sørensen, E Manniche, B Holten, IA Weibull and A Ortman.
Authors also want to thank to C Garcia-Rizo for inspiring this work and Professor E Vieta for his valuable support.

\section{Appendix A. Supplementary data}

Supplementary material related to this article can be found, in the online version, at doi:https://doi.org/10.1016/j.eurpsy.2019.08.015.

\section{References}

[1] De Hert M, Correll CU, Bobes J, Cetkovich-Bakmas M, Cohen D, Asai I, et al. Physical illness in patients with severe mental disorders. I. Prevalence, impact of medications and disparities in health care. World Psychiatry 2011;10:52-77.

[2] Stubbs B, Vancampfort D, De Hert M, Mitchell AJ. The prevalence and predictors of type two diabetes mellitus in people with schizophrenia: a systematic review and comparative meta-analysis. Acta Psychiatr Scand 2015;132:144-57, doi:http://dx.doi.org/10.1111/acps.12439.

[3] Kucukgoncu S, Kosir U, Zhou E, Sullivan E, Srihari VH, Tek C. Glucose metabolism dysregulation at the onset of mental illness is not limited to first episode psychosis: a systematic review and meta-analysis. Early Interv Psychiatry 2018, doi:http://dx.doi.org/10.1111/eip.12749.

[4] Vancampfort D, Mitchell AJ, De Hert M, Sienaert P, Probst M, Buys R, et al. Prevalence and predictors of type 2 diabetes mellitus in people with bipolar disorder. J Clin Psychiatry 2015;76:1490-9, doi:http://dx.doi.org/10.4088/JCP.14r09635.

[5] Yu M, Zhang X, Lu F, Fang L. Depression and risk for diabetes: a meta-analysis. Can J Diabetes 2015;39:266-72, doi:http://dx.doi.org/10.1016/j. jcjd.2014.11.006.

[6] Vancampfort D, Correll CU, Galling B, Probst M, De Hert M, Ward PB, et al. Diabetes mellitus in people with schizophrenia, bipolar disorder and major depressive disorder: a systematic review and large scale meta-analysis. World Psychiatry 2016;15:166-74, doi:http://dx.doi.org/10.1002/wps.20309.

[7] de Leon J, Diaz FJ. A meta-analysis of worldwide studies demonstrates an association between schizophrenia and tobacco smoking behaviors. Schizophr Res 2005;76:135-57, doi:http://dx.doi.org/10.1016/j.schres.2005.02.010.

[8] Scott D, Happell B. The high prevalence of poor physical health and unhealthy lifestyle behaviours in individuals with severe mental illness. Issues Ment Health Nurs 2011;32:589-97, doi:http://dx.doi.org/10.3109/ 01612840.2011 .569846 .

[9] Vancampfort D, Knapen J, Probst M, Scheewe T, Remans S, De Hert M. A systematic review of correlates of physical activity in patients with schizophrenia. Acta Psychiatr Scand 2012;125:352-62, doi:http://dx.doi.org/ 10.1111/j.1600-0447.2011.01814.x.

[10] Vancampfort D, De Hert M, Stubbs B, Ward PB, Rosenbaum S, Soundy A, et al. Negative symptoms are associated with lower autonomous motivation towards physical activity in people with schizophrenia. Compr Psychiatry 2015;56:128-32, doi:http://dx.doi.org/10.1016/j.comppsych.2014.10.007.

[11] De Leon J, Diaz FJ. A meta-analysis of worldwide studies demonstrates an association between schizophrenia and tobacco smoking behaviors. Schizophr Res 2005;76:135-57, doi:http://dx.doi.org/10.1016/j.schres.2005.02.010.

[12] Gierisch JM, Nieuwsma JA, Bradford DW, Wilder CM, Mann-Wrobel MC, McBroom AJ, et al. Pharmacologic and behavioral interventions to improve cardiovascular risk factors in adults with serious mental illness: a systematic review and meta-analysis. J Clin Psychiatry 2014;75:e424-40, doi:http://dx. doi.org/10.4088/JCP.13r08558.

[13] Cariaga-Martinez A, Alelú-Paz R. Rethinking the Epigenetic Framework to Unravel the Molecular Pathology of Schizophrenia. Int J Mol Sci 2017;18:, doi: http://dx.doi.org/10.3390/ijms18040790.

[14] Radhakrishnan R, Kaser M, Guloksuz S. The link between the immune system, environment, and psychosis. Schizophr Bull 2017;43:693-7, doi:http://dx.doi org/10.1093/schbul/sbx057.

[15] Ridout KK, Levandowski M, Ridout SJ, Gantz L, Goonan K, Palermo D, et al. Early life adversity and telomere length: a meta-analysis. Mol Psychiatry 2018:23:858-71, doi:http://dx.doi.org/10.1038/mp.2017.26.

[16] Garcia-Rizo C, Kirkpatrick B, Fernandez-Egea E, Oliveira C, Bernardo M. Abnormal glycemic homeostasis at the onset of serious mental illnesses: a common pathway. Psychoneuroendocrinology 2016;67:70-5, doi:http://dx. doi.org/10.1016/j.psyneuen.2016.02.001.

[17] Garcia-Rizo C, Fernandez-Egea E, Bernardo M, Kirkpatrick B. The thrifty psychiatric phenotype. Acta Psychiatr Scand 2015;131:18-20, doi:http://dx. doi.org/10.1111/acps.12309.

[18] Hales CN, Barker DJ. Type 2 (non-insulin-dependent) diabetes mellitus: the thrifty phenotype hypothesis. Diabetologia 1992;35:595-601.

[19] Barker DJ. Maternal nutrition, fetal nutrition, and disease in later life. Nutrition 1997:13:807-13.

[20] Portella AK, Kajantie E, Hovi P, Desai M, Ross MG, Goldani MZ, et al. Effects of in utero conditions on adult feeding preferences. J Dev Orig Health Dis 2012:3:140-52, doi:http://dx.doi.org/10.1017/S2040174412000062.

[21] Martyn CN, Barker DJ, Jespersen S, Greenwald S, Osmond C, Berry C. Growth in utero, adult blood pressure, and arterial compliance. Br Heart J 1995;73:116-21.

[22] Hales CN, Barker DJP. Type 2 (non-insulin-dependent) diabetes mellitus: the thrifty phenotype hypothesis. Int J Epidemiol 1992;2013(42):1215-22, doi: http://dx.doi.org/10.1093/ije/dyt133. 
[23] Barker DJ. Intrauterine programming of coronary heart disease and stroke. Acta Paediatr 1997;423(Supplement)178-82 discussion 183.

[24] Ahlgren M, Wohlfahrt J, Olsen LW, Sørensen TIA, Melbye M. Birth weight and risk of cancer. Cancer 2007;110:412-9, doi:http://dx.doi.org/10.1002/cncr.22773.

[25] Mathewson KJ, Chow CHT, Dobson KG, Pope EI, Schmidt LA, Van Lieshout RJ. Mental health of extremely low birth weight survivors: a systematic review and meta-analysis. Psychol Bull 2017;143:347-83, doi:http://dx.doi.org/ 10.1037/bul0000091.

[26] Schlotz W, Phillips DIW. Fetal origins of mental health: evidence and mechanisms. Brain Behav Immun 2009;23:905-16, doi:http://dx.doi.org/ 10.1016/j.bbi.2009.02.001.

[27] Breslau N, Chilcoat HD. Psychiatric sequelae of low birth weight at 11 years of age. Biol Psychiatry 2000;47:1005-11.

[28] Wiles NJ, Peters TJ, Heron J, Gunnell D, Emond A, Lewis G. Fetal growth and childhood behavioral problems: results from the ALSPAC cohort. Am J Epidemiol 2006;163:829-37, doi:http://dx.doi.org/10.1093/aje/kwj108.

[29] Sucksdorff M, Lehtonen L, Chudal R, Suominen A, Joelsson P, Gissler M, et al. Preterm birth and poor fetal growth as risk factors of attention-deficit/ hyperactivity disorder. Pediatrics 2015;136:e599-608, doi:http://dx.doi.org/ 10.1542/peds.2015-1043.

[30] Osler M, Nordentoft M, A-MN Andersen. Birth dimensions and risk of depression in adulthood: cohort study of Danish men born in 1953. The British Journal of Psychiatry: The Journal of Mental Science 2005;186:400-3, doi: http://dx.doi.org/10.1192/bjp.186.5.400.

[31] Abel KM, Wicks S, Susser ES, Dalman C, Pedersen MG, Mortensen PB, et al. Birth weight, schizophrenia, and adult mental disorder: is risk confined to the smallest babies? Arch Gen Psychiatry 2010;67:923-30, doi:http://dx.doi.org/ 10.1001/archgenpsychiatry.2010.100.

[32] Van den Bergh BRH, van den Heuvel MI, Lahti M, Braeken M, de Rooij SR, Entringer S, et al. Prenatal developmental origins of behavior and mental health: the influence of maternal stress in pregnancy. Neurosci Biobehav Rev 2017, doi:http://dx.doi.org/10.1016/j.neubiorev.2017.07.003.

[33] O’Donnell KJ, Meaney MJ. Fetal origins of mental health: the developmenta origins of health and disease hypothesis. Am J Psychiatry 2017;174:319-28, doi:http://dx.doi.org/10.1176/appi.ajp.2016.16020138.

[34] Whincup PH, Kaye SJ, Owen CG, Huxley R, Cook DG, Anazawa S, et al. Birth weight and risk of type 2 diabetes. JAMA 2008;300:2886, doi:http://dx.doi. org/10.1001/jama.2008.886.

[35] Harder T, Rodekamp E, Schellong K, Dudenhausen JW, Plagemann A. Birth weight and subsequent risk of type 2 diabetes: a meta-analysis. Am J Epidemiol 2007;165:849-57, doi:http://dx.doi.org/10.1093/aje/kwk071.

[36] Suvisaari JM, Taxell-Lassas V, Pankakoski M, Haukka JK, Lonnqvist JK, Hakkinen LT. Obstetric complications as risk factors for schizophrenia Spectrum psychoses in offspring of mothers with psychotic disorder. Schizophr Bull 2012 doi:sbs109 [pii]10.1093/schbul/sbs109.

[37] Mezquida G, Fernandez-Egea E, Treen D, Mané A. Bergé D, Savulich G, et al. Obstetric phenotypes in the heterogeneity of schizophrenia. J Nerv Ment Dis 2018;206:882-6, doi:http://dx.doi.org/10.1097/NMD.0000000000000897.

[38] Fernandez-Egea E, Bernardo M, Donner T, Conget I, Parellada E, Justicia A, et al. Metabolic profile of antipsychotic-naive individuals with non-affective psychosis. Br J Psychiatry 2009;194:434-8, doi:http://dx.doi.org/10.1192/bjp. bp.108.052605.

[39] Osler M, Lund R, Kriegbaum M, Christensen U, A-MN Andersen. Cohort profile: the Metropolit 1953 Danish male birth cohort. Int J Epidemiol 2006;35:541-5, doi:http://dx.doi.org/10.1093/ije/dyi300.

[40] Crusell M, Damm P, Hansen T, Pedersen O, Glümer C, Vaag A, et al. Ponderal index at birth associates with later risk of gestational diabetes mellitus. Arch Gyneco Obstet 2017;296:249-56, doi:http://dx.doi.org/10.1007/s00404-017-4427-4.
[41] Mortensen EL, Reinisch JMTT. Intelligence as measured by the WAIS and military draft board group test. Scand J Psychol 1989;30:315-8.

[42] Rajkumar AP, Horsdal HT, Wimberley T, Cohen D, Mors O, Børglum AD, et al. Endogenous and Antipsychotic-Related Risks for Diabetes Mellitus in Young People With Schizophrenia: A Danish Population-Based Cohort Study. Am J Psychiatry 2017;174:686-94, doi:http://dx.doi.org/10.1176/appi. ajp.2016.16040442.

[43] Holt RIG, Mitchell AJ. Diabetes mellitus and severe mental illness: mechanisms and clinical implications. Nat Rev Endocrinol 2015;11:79-89, doi:http://dx. doi.org/10.1038/nrendo.2014.203.

[44] Van den Bergh BRH. Developmental programming of early brain and behaviour development and mental health: a conceptual framework. Dev Med Child Neurol 2011;53(Suppl 4):19-23, doi:http://dx.doi.org/10.1111/ j.1469-8749.2011.04057.x.

[45] Ziauddeen H, Garcia-Rizo C, Bernardo M, Kirkpatrick B, Ozanne SE, Jones PB, et al. Association of birth weight and the development of antipsychotic induced adiposity in individuals with treatment resistant schizophrenia. Eur Neuropsychopharmacol 2016;26:972-8, doi:http://dx.doi.org/10.1016/j. euroneuro.2016.03.008

[46] Garriga M, Fernandez-Egea E, Mallorqui A, Serrano L, Oliveira C, Parellada E, et al. Antipsychotic-induced weight gain and birth weight in psychosis: a fetal programming model. J Psychiatr Res 2019;115:29-35, doi:http://dx.doi.org/ 10.1016/j.jpsychires.2019.05.004

[47] O'Donnell KJ, Meaney MJ. Fetal origins of mental health: the developmental origins of health and disease hypothesis. Am J Psychiatry 2017:174:319-28, doi:http://dx.doi.org/10.1176/appi.ajp.2016.16020138.

[48] Correll CU, Solmi M, Veronese N, Bortolato B, Rosson S, Santonastaso P, et al. Prevalence, incidence and mortality from cardiovascular disease in patients with pooled and specific severe mental illness: a large-scale meta-analysis of $3,211,768$ patients and 113,383,368 controls. World Psychiatry 2017;16:16380, doi:http://dx.doi.org/10.1002/wps.20420.

[49] Kessing LV, Thomsen AF, Mogensen UB, Andersen PK. Treatment with antipsychotics and the risk of diabetes in clinical practice. The British Journal of Psychiatry: The Journal of Mental Science 2010;197:266-71, doi: http://dx.doi.org/10.1192/bjp.bp.109.076935.

[50] Knyahnytska Y, Williams C, Dale C, Webster F. Changing the conversation: diabetes management in adults with severe mental illnesses and type 2 diabetes. Can J Diabetes 2018;42:595-602, doi:http://dx.doi.org/10.1016/j. jcjd.2018.02.001.

[51] Pillinger T, Beck K, Gobjila C, Donocik JG, Jauhar S, Howes OD. Impaired Glucose Homeostasis in First-Episode Schizophrenia: A Systematic Review and Metaanalysis. JAMA Psychiatry 2017;74:261-9, doi:http://dx.doi.org/10.1001/ jamapsychiatry.2016.3803.

[52] Zhao H, Song A, Zhang Y, Zhen Y, Song G, Ma H. The association between birth weight and the risk of type 2 diabetes mellitus: a systematic review and metaanalysis. Endocr J 2018;65:923-33, doi:http://dx.doi.org/10.1507/endocrj. EJ18-0072.

[53] Mangurian C, Schillinger D, Newcomer JW, Vittinghoff E, Essock S, Zhu Z, et al. Diabetes screening among antipsychotic-treated adults with severe mental illness in an integrated delivery system: a retrospective cohort study. J Gen Intern Med 2018;33:79-86, doi:http://dx.doi.org/10.1007/s11606-017-4205-9.

[54] Nilsson E, Lichtenstein P, Cnattingius S, Murray RM, Hultman CM. Women with schizophrenia: pregnancy outcome and infant death among their offspring. Schizophr Res 2002;58:221-9.

[55] Hepgul N, Pariante CM, Dipasquale S, DiForti M, Taylor H, Marques TR, et al. Childhood maltreatment is associated with increased body mass index and increased C-reactive protein levels in first-episode psychosis patients. Psychol Med 2012;42:1893-901, doi:http://dx.doi.org/10.1017/S0033291711002947. 